\title{
Jatos ou Turboélices: Eficiência no consumo de combustível através de análise envoltória de dados
}

\section{Carlos Higino Marques Junior ${ }^{1}$, Giovanna Miceli Ronzani Borille ${ }^{2}$, Luciana Lins de Mello ${ }^{3}$, Rogéria de Arantes Gomes Eller ${ }^{4}$}

${ }^{1}$ Instituto Tecnológico de Aeronáutica, ITA, carloshiginojr@gmail.com

2Instituto Tecnológico de Aeronáutica, ITA, ronzani@ita.br

3Instituto Tecnológico de Aeronáutica, ITA, mellolu@yahoo.com

4Instituto Tecnológico de Aeronáutica, ITA, rogeria@ita.br

\section{Recebido: \\ 28 de outubro de 2017 \\ Aceito para publicação: \\ 12 de junho de 2018 \\ Publicado: \\ 31 de dezembro de 2018 \\ Editor de área: \\ Li Weigang}

\section{Palavras-chaves:}

Turboélice,

Jato,

Combustivel,

Custo,

Meio ambiente,

Linha aérea.

\section{Keywords:}

Turboprop,

Jet,

Fuel,

Cost,

Environment,

Airline.

DOI:10.14295/transportes.v26i4.1494

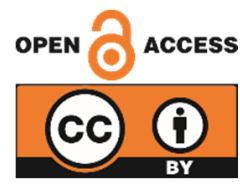

\begin{abstract}
RESUMO
$\mathrm{Na}$ indústria aeronáutica, o combustível é um dos mais caros insumos e, com o incessável desejo por redução de custos, as companhias aéreas buscam a otimização de suas frotas através da seleção do conjunto aeronave e motor mais eficiente para as rotas e frequências que operam. Dentro deste contexto, o presente artigo estuda o consumo de combustível de quatro companhias aéreas estadunidenses, sendo: (i) uma com frota composta exclusivamente por jatos regionais, (ii) outra por turboélices, (iii) uma terceira por jatos narrowbodies e (iv) uma quarta com frota mista de jatos regionais e turboélices. A contribuição deste trabalho reside na verificação da eficiência no consumo de combustível através de uma Análise Envoltória de Dados (DEA) tendo como premissas retorno de escala constante (CRS) e variável (VRS). Os resultados indicam que as frotas (ii) e (iii) são mais eficientes que as frotas (i) e (iv) quando se utiliza modelo DEA CRS. A abordagem VRS, no entanto, demonstra que as quatro empresas são igualmente eficientes no consumo de combustível. Ou seja, as frotas (i) e (iv) já apresentariam as meIhores práticas, mas enfrentariam problema de escala. No entanto, não é possível afirmar categoricamente que os resultados se devem exclusivamente ao tipo de frota dado os diferentes mercados de atuação de cada empresa.
\end{abstract}

\begin{abstract}
In the aeronautics industry, fuel is one of the most expensive inputs and with the unrelenting aim to diminish costs, airlines look to optimize their fleets by assigning the most economic aircraft engine type to specific routes and frequencies. This paper studies fuel consumption of four North American airlines: (i) one fleet exclusively composed by regional jets, (ii) one composed exclusively by turboprops, (iii) a third flying narrowbodies jets and (iv) a fourth with a mixed fleet of turboprops and regional jets. Contribution from this paper relies on checking airlines' fuel efficiency through a DEA (Data Envelopment Analysis) model considering both constant (CRS) and variable (VRS) returns of scale. Results indicate that fleet (ii) and (iii) are more efficient than fleet (i) and (iv) through DEA CRS. VRS approach, however, indicates that four companies are equally fuel efficient. That is, fleet (i) and (iv) already have best practices but faces scale problems. Nonetheless, it is not possible to categorically state that results are solely driven by fleet type since each company plays in different markets.
\end{abstract}

\section{INTRODUÇÃO}

A presente pesquisa visa analisar a eficiência no consumo de combustível através de uma Análise Envoltória de Dados, DEA, de quatro companhias aéreas que operam aeronaves com diferentes tipos de motorização. Este estudo permite também o reconhecimento das características de consumo de combustível de duas tecnologias de motores: turboélices e jatos. Para atingir o 
objetivo, são utilizados dados de consumo de 2015 das empresas indicadas na Tabela 1 com suas correspondentes aeronaves.

Tabela 1 - Seleção das empresas para estudo e respectiva frota, por tipo de motor

\begin{tabular}{ll}
\hline Empresa & Tipo de motor e aeronave \\
\hline Air Wisconsin - AW & Jatos regionais \\
Island Air - IA & Turboélices \\
Republic Airlines - RA & Jatos e turboélices \\
Sun Country - SC & Jatos narrowbodies \\
\hline
\end{tabular}

Os motores turboélices e os motores a jato - com suas respectivas variações - se diferem principalmente pelo encapsulamento ou não das hélices e de sua velocidade de rotação, mais lenta em turboélices. Do modo técnico, aviões turboélices, também conhecidos como turboprops, utilizam uma turbina a gás de combustão interna que move uma hélice convencional. Os aviões a jato, conhecidos em inglês como turbojets, utilizam o mesmo tipo de turbina como gerador de gás e um bocal de propulsão como produtor de impulso. Os jatos possuem uma variação conhecida como turbofan. Neste modelo, parte do empuxo é obtida desviando uma porção do ar de entrada da câmara de combustão, e o ar desviado proporciona empuxo de modo semelhante aos motores turboélices (BONACCORSI; GIURI, 2000). Motores a jato do tipo geared turbofans, em operação desde 2015, não foram considerados neste estudo.

0 custo do combustível influencia fortemente os custos totais de uma empresa aérea e, medidas que levam à redução desse custo são relevantes para o desempenho financeiro da empresa. Devido às diferenças no consumo de querosene de aviação, combustível utilizado por aeronaves de grande porte, a escolha entre estes motores é amplamente discutida, principalmente desde 2008 quando o preço do barril de petróleo se aproximou dos USD 140. Mesmo com o preço do barril de petróleo oscilando em torno de USD 50 desde o último trimestre de 2014, o monitoramento do consumo de combustível permanece relevante; visto que as companhias aéreas nem sempre se beneficiam desta redução na mesma proporção. Sendo o petróleo cotado em dólares estadunidenses, empresas operando em países em que a moeda local se desvalorizou frente ao dólar percebem menor diminuição nos custos com combustível, e assim, continuariam possuindo motivos para buscar o conjunto aeronave-motor mais econômico para suas rotas e frequências de operação, ainda que seu efeito seja percebido no longo prazo.

Além do custo do insumo em si, há também o custo ambiental coexistente no uso de combustível fóssil. Iniciativas governamentais têm incentivado a indústria aeronáutica a reduzir as emissões de gases de efeito estufa por meio de uma variedade de instrumentos, como possíveis taxas de carbono e a inclusão da aviação no sistema de cap-and-trade da União Europeia (RYERSON; HANSEN, 2010).

Assim como Karlaftis e Tsamboulas (2012), este trabalho considera eficiência como a comparação entre os valores reais de produtos e insumos em relação aos respectivos valores ótimos utilizados no processo de produção. Todavia, ao se utilizar o método DEA, o termo eficiência passa a ser uma medida de referência em relação às melhores práticas representadas por aquela empresa que gera mais produtos com menor quantidade de insumos - ou menor quantidade de combustível no contexto deste trabalho. A adoção do DEA fundamentou-se no trabalho de ZOU et al. (2014) que, ao compararem diferentes metodologias de análise de eficiência no consumo de combustível, concluíram que os resultados do modelo DEA, proposto por Tofallis (1997), foram consistentes com outros métodos por eles estudados. 
Este trabalho está dividido em cinco partes. Na primeira parte é apresentada a introdução ao tema, sua relevância e objetivo da pesquisa. Na segunda, é discutida a revisão da literatura enquanto a terceira traz uma breve explanação a respeito do método DEA. A quarta parte descreve a metodologia do trabalho enquanto a quinta contém a descrição da aplicação. Na sexta parte são mostrados e discutidos os resultados da análise e, por fim, na sétima parte são apresentadas as considerações finais.

\section{REVISÃO DE LITERATURA}

O custo operacional de uma companhia aérea é definido por Ryerson e Hansen (2010) como sendo a soma dos custos com combustível, tripulação, manutenção e serviços aeroportuários. Estudo de Babikian, Lukachko e Waitz (2002) relatam que o combustível representa uma das maiores partes do custo operacional total das companhias aéreas, sendo: quase $22 \%$ para jatos grandes, 17\% para jatos regionais e 13\% para os turboélices. De acordo com dados de 2017 da ABEAR, Associação Brasileira das Empresas Aéreas, o custo com combustível representou, em média, 42\% dos custos operacionais brasileiros entre os anos de 2002 e 2015. Tal qual exposto por Ryerson e Hansen (2010), estes percentuais se alteram conforme a variação do preço do combustível, sendo mais suscetíveis a estas variações as aeronaves que servem mercados de curta distância.

Podendo ser estimado pela equação de Breguet, indicada na Equação 1, o consumo de combustível é função do projeto da aeronave - aerodinâmica, massa e eficiência dos motores - e de características do voo como técnicas de pilotagem, payload, perfil de voo e tempo de rolagem na pista. Além de prover energia de propulsão para movimentar aeronaves, motores também têm sua energia convertida em energia elétrica, hidráulica e pneumática (TONA et al., 2010). Ou seja, a eficiência no consumo de combustível é também dependente da quantidade de sistemas acionados pelos motores e da eficiência destes respectivos sistemas.

$$
R=\frac{V \cdot(L / D)}{g \cdot T S F C} \cdot \ln \left(\frac{w_{i}}{w_{f}}\right)
$$

Conforme o voo ocorre, reduz-se a massa total da aeronave em função do consumo de combustível; e, portanto, a diferença entre a massa inicial $\mathbf{W}_{\mathbf{i}}$ e massa final $\mathbf{W}_{\mathbf{f}}$ da aeronave corresponde ao próprio consumo de combustível durante um voo em determinada altitude com velocidade constante. Enquanto $\mathbf{V}$ representa a velocidade do voo e $\mathbf{R}$ a distância percorrida durante o voo, TSFC refere-se ao consumo específico de combustível e L/D à razão aerodinâmica entre sustentação e arrasto da aeronave. A letra g corresponde à aceleração da gravidade terrestre.

O consumo específico de combustível TSFC é uma medida de eficiência do motor dependente de seu projeto e indica a potência produzida por unidade de fluxo de combustível num dado período. Turboélices são de 10 a 30\% mais eficientes durante a fase de cruzeiro que motores a jato, i.e., geram mais potência por unidade de combustível. Parte significativa da diferença no consumo de combustível é justificada pela capacidade que os turboélices têm de acelerar grande massa de ar em baixa velocidade. Esta mesma capacidade, porém, limita a altitude de voo dos turboélices a 7,6 km (BABIKIAN; LUKACHKO; WAITZ, 2002).

Objetivando a comparação entre conjuntos aeronave-motor, Babikian, Lukachko e Waitz (2002) calcularam a energia consumida Eu - combustível, por extensão - para transportar um assento durante 1 quilômetro para diferentes tamanhos de etapa de voo. Concluíram que Eu reduz conforme se aumenta a distância voada como indica a Figura 1. A análise baseia-se na 
equação de Breguet e os resultados demonstram que jatos em voos inferiores a $1000 \mathrm{~km}$ possuem Eu entre 1,5 e 3 vezes maior que jatos em voos com distâncias superiores a esta. Considerando voos de mesma distância, jatos regionais são entre $10 \%$ e $60 \%$ menos eficientes que aviões turboélices, mas apesar disto, como maior investimento em tecnologia é feito em jatos e seus motores, sua eficiência melhora rapidamente com o tempo. Babikian, Lukachko e Waitz (2002) ressaltam também que para uma mesma distância, encontraram tanto turboélices mais econômicos que jatos, quanto jatos mais econômicos que turboélices. Atribuem este fato a variações no nível tecnológico de cada aeronave.

0 resultado apresentado na Figura 1 se deve também a questões operacionais, pois pequenos aviões tendem a voar distâncias menores, e assim, o tempo em solo - taxiando e manobrando é proporcionalmente maior em comparação aos grandes aviões. Além disto, o tempo de subida de uma aeronave, que é a fase menos econômica, representa parcela significativa do voo em rotas curtas. Como aeronaves turboélices voam em altitudes menores que jatos, despendem menos tempo subindo e assim, possuem melhor eficiência que jatos quando ambos voam rotas curtas (BABIKIAN; LUKACHKO; WAITZ, 2002).

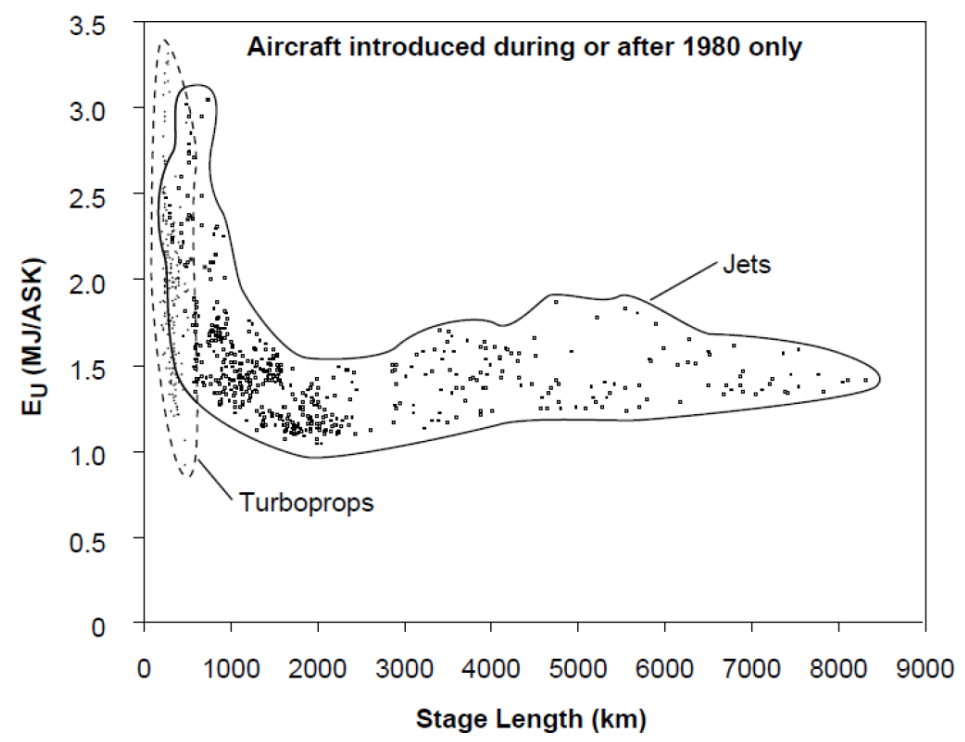

Figura 1 - Uso de Energia em função do tamanho da etapa (BABIKIAN; LUKACHKO; WAITZ, 2002).

A velocidade com a qual um voo é desempenhado interfere na quantidade de combustível consumido. Há, para cada modelo de aeronave, a velocidade MRS - maxi range speed - que maximiza o alcance e garante maior economia de combustível. A velocidade mais utilizada por companhias aéreas é a de longo alcance que é até 5\% maior que MRS, mas com consumo de combustível apenas 1\% mais elevado (REINAS; MARIANO; REBELATTO, 2011).

Um voo mais rápido é interessante, pois aumenta a produtividade das aeronaves, isto é, permite a realização de mais voos num mesmo período de tempo. Como os turboélices voam em velocidades menores que jatos, consomem mais tempo para cumprir o mesmo trajeto; e desta forma, jatos permitem o aumento de frequência de voos. 0 ganho econômico resultante da maior produtividade, no entanto, pode ser reduzido em função do preço do combustível dado o consumo maior de combustível pelos jatos.

Quando se comparam custos operacionais por assento por unidade de distância, Brueckner e Pai (2009) indicam que turboélices são mais econômicos que jatos regionais, mas que ambas 
aeronaves apresentam piores resultados que jatos maiores. Situação semelhante foi percebida por Ryerson e Hansen (2010) quando compararam jatos de aproximadamente 50 assentos e turboélices de aproximadamente 70 assentos e concluíram que os jatos sempre apresentam custos superiores aos turboélices para voos de até $1852 \mathrm{~km}$. A situação se modifica quando Ryerson e Hansen (2010) comparam jatos com aproximadamente 130 assentos e os turboélices: os narrowbodies são economicamente mais vantajosos quanto menor for o preço do combustível e quanto maior for a distância voada.

De acordo com Ryerson e Hansen (2010), o tamanho máximo para que uma rota seja economicamente viável, ou seja, apresente menor custo operacional por assento, voando turboélices aumenta conforme o preço do combustível aumenta. ZOU et al. (2014) relembram que o grande interesse de uma companhia aérea, como de todas as outras empresas, é maximizar seus lucros e que para tal, deixariam de investir em uma frota mais eficiente caso a frota existente proporcionasse maiores lucros. 0 menor custo operacional de turboélices, entretanto, diminui o ponto de equilíbrio para o qual o transporte aéreo se torna economicamente viável, permitindo que companhias aéreas sirvam maior quantidade de destinos incluindo rotas curtas. Desta forma, elas conseguem aumentar sua dominância no mercado e aumentar as tarifas (RYERSON; GE, 2014).

Givoni e Rietveld (2010) investigam a relação entre a escolha do tamanho da aeronave, a frequência de serviço prestado pelas companhias aéreas, e as implicações ambientais dessas operações. Eles analisam a poluição local, a mudança climática e o impacto de ruído resultante deste modelo de produção, avaliando se o ambiente competitivo que impulsiona as companhias aéreas a oferecer um serviço de alta frequência carregaria uma penalidade ambiental. A conclusão do estudo indica que a redução de movimentos de aeronaves quando aumentado o tamanho das aeronaves pode proporcionar redução do consumo de combustível como benefício ambiental (GIVONI; RIETVELD, 2010). Dados de Babikian, Lukachko e Waitz (2002) corroboram, por outro ponto de vista, esta opinião quando afirmam que a razão massa do avião por carga paga transportada é maior em pequenas aeronaves a jato e turboélices que em grandes aviões.

O mercado de curta distância para grandes aviões depende da comprovação de redução do consumo de combustível. Isso é possível quando se trabalha com load factor - razão entre o número de passageiros pagantes e o número de assentos ofertados por voo - maior e com frequência menor. Novos aumentos substanciais no preço do combustível e a existência de um mecanismo que quantifique a externalidade ambiental são razões para se desenvolver a prática de operar grandes aviões em curtas distâncias (GIVONI; RIETVELD, 2010).

A revisão de literatura evidencia os benefícios do turboélice em rotas menores, sendo o maior benefício o menor consumo de combustível, quando comparado ao jato. Contudo, há indícios que diminuindo a frequência dos voos e atendendo a demanda com uma aeronave maior, o mesmo efeito seria evidenciado: corte no consumo de combustível.

\section{ANÁLISE ENVOLTÓRIA DE DADOS - DEA}

DEA é um método comparativo que delimita uma fronteira de eficiência de uma companhia frente àquela companhia que apresenta maior produção com menor quantidade de insumos. Empregando programação linear, este tipo de análise não explicita uma função de produção para cada companhia, mas indica o grau de ineficiência de uma companhia em relação àquela considerada mais eficiente pelo método.

Dado que o desempenho calculado para cada companhia é otimizado no DEA, sua eficiência 
tende a ser superestimada (SHERMAN; ZHU, 2006) e consequentemente, grande quantidade de companhias pode ser considerada eficiente (TOFALLIS, 1997). Assim, Tofallis (1997) propõe que a eficiência na utilização dos insumos seja analisada individualmente e não na abordagem tradicional de múltiplos insumos e múltiplos produtos. Uma exceção é feita quando os insumos são substituíveis entre si.

A programação linear do modelo DEA proposta por ZOU et al. (2014) e Tofallis (1997), é apresentada a seguir; primeiramente considerando retornos de escala constante - CRT - nas Equações 2, 3, 4 e 5; e posteriormente considerando retorno de escala variável - VRT nas Equações 6, 7, 8, 9 e 10 :

Sujeito a:

$$
\min _{\theta, \lambda} \theta
$$

Sujeito a:

$$
\begin{gathered}
\theta \cdot x_{0}-\boldsymbol{X} \cdot \boldsymbol{\lambda} \geq 0 \\
\boldsymbol{Y} \cdot \boldsymbol{\lambda}=\boldsymbol{y}_{\mathbf{0}} \\
\boldsymbol{\lambda} \geq \mathbf{0} \\
\min _{\theta, \lambda} \theta
\end{gathered}
$$

$$
\begin{gathered}
\theta \cdot x_{0}-\boldsymbol{X} \cdot \boldsymbol{\lambda} \geq 0 \\
\boldsymbol{Y} \cdot \boldsymbol{\lambda}=\boldsymbol{y}_{\mathbf{0}} \\
\boldsymbol{e} \cdot \boldsymbol{\lambda}=1 \\
\boldsymbol{\lambda} \geq \mathbf{0}
\end{gathered}
$$

Enquanto $\mathbf{X}$ e $\mathbf{Y}$ são, respectivamente, o insumo e os produtos do modelo das companhias aéreas analisadas, o subscrito $\mathbf{0}$ indica a companhia aérea sob análise; e é um vetor unitário, enquanto $\theta$ e o vetor $\lambda$ - com um valor para cada empresa - são as variáveis de decisão, sendo $\theta$ o índice de eficiência. A única diferença entre as duas formulações é a igualdade $\mathbf{e} \cdot \lambda=1$ que impõe condição de convexidade na formulação VRS. Esta restrição faz com que a solução VRS seja um subconjunto da solução CRS. 0 valor ótimo de $\theta$ no VRS, portanto, nunca é maior que aquele encontrado no CRS. A solução dos sistemas fornece o índice de ineficiência de cada empresa no período analisado.

\section{METODOLOGIA DE PESQUISA}

Analisou-se, para cada uma das quatro companhias aéreas, o montante de assentos disponíveis (seat), a quantidade de passageiros (pax) e total de carga paga transportados (payload), a quantidade de voos efetuados (voo), a distância percorrida (dist) e o consumo de combustível (comb) no período de um ano. Estas informações foram consolidadas em cinco índices de consumo de combustível discriminados nas Equações 11, 12, 13, 14 e 15 a seguir:

$$
\begin{aligned}
\text { Índice } 1 & =\frac{\text { comb }}{\text { seat }} \\
\text { Índice } 2 & =\frac{\text { comb }}{v o o} \\
\text { Índice } 3 & =\frac{\text { comb }}{\text { dist }} \\
\text { Índice } 4 & =\frac{\text { comb }}{\text { pax }} \\
\text { Índice } 5 & =\frac{\text { comb }}{\text { payload }}
\end{aligned}
$$

Os dois primeiros índices foram selecionados pois, normalmente, custos operacionais são estabelecidos por assento ou por viagem. 0 terceiro foi escolhido para dimensionar o desempenho dos motores em sua função básica: mover a aeronave por determinado espaço. 0 quarto foi selecionado para quantificar o load factor e como compensação ao primeiro, pois o produto final 
de uma aeronave são passageiros transportados e não assentos. Já o quinto foi escolhido como um parâmetro de comparação mais representativo das operações aéreas cotidianas, dado que nem sempre os voos são efetuados utilizando-se a capacidade total da aeronave, ou seja, permite a identificação de eventual substituição de passageiros por malotes postais em períodos de baixa demanda por viagens aéreas. Acredita-se que a utilização do quinto índice forneceria uma comparação mais justa entre o desempenho dos motores, expurgando características próprias das quatro empresas e do mercado em que operam.

Numa etapa posterior, os dados publicados pelo Bureau of Transportation Statistics, BTS, foram examinados e confrontados através do DEA considerando tanto CRT quanto VRT. Utilizouse como insumo do DEA a quantidade de combustível consumida. Como produtos, considerouse a quantidade de passageiros transportados, a quantidade de voos realizados e a distância total percorrida no período.

A programação linear utilizada neste estudo é idêntica àquela utilizada por Zou et al. (2014) exceto pela quantidade de produtos considerados. Enquanto o presente estudo considera a quantidade de passageiros transportados, a quantidade de voos realizados e a distância total percorrida como produtos, Zou et al. (2014) consideraram como produto a quantidade de voos efetuados e o produto agregado RPM - passageiros transportados por milha voada.

\section{APLICAÇÃO}

Considerando que uma companhia aérea se esforce ao máximo para voar suas aeronaves em seu ponto de eficiência, DEA auxilia o entendimento do desempenho de cada aeronave nas rotas operadas, permitindo a identificação da frota mais eficiente. As quatro companhias aéreas estadunidenses selecionadas neste estudo com base em sua frota são: Air Wisconsin, operando jatos regionais, Island Air, operando aeronaves turboélices, Republic Airlines, operando tanto jatos regionais quanto turboélices e Sun Country operando jatos narrowbodies.

A análise restringiu-se aos dados compreendidos entre janeiro e dezembro de 2015, pois este foi o único período em que (i) as quatro companhias mantiveram frota dentro dos critérios que levaram à sua seleção e que (ii) suas informações estavam disponíveis simultaneamente na base do BTS. Outrossim, foram consideradas apenas as rotas domésticas como medida para equiparar as amostras e evitar distorções nos resultados obtidos.

Fundada em 1980 como Princeville Airways, a Island Air opera no Havaí sob essa marca desde 1992. Em fevereiro de 2013 a companhia recebeu a certificação da FAA para operar turboélices com capacidade de 64 passageiros e iniciou a renovação de sua frota. Atualmente, a Island Air oferece mais de 250 voos semanais entre ilhas havaianas utilizando 5 turboélices bimotores com hélices de quatro pás. Sua maior rota possui $285 \mathrm{~km}$.

Operando voos charter desde 1982, a Sun Country Airlines é uma companhia aérea estadunidense que oferece tanto voos domésticos quanto internacionais nas Américas do Norte e Central, utilizando 23 jatos narrowbodies configurados para 126 a 174 passageiros e equipados com dois motores. É em Minneapolis que a Sun Country opera 45,12\% de seus voos, cujo principal par origem-destino dista em aproximadamente $3070 \mathrm{~km}$.

Existente desde 1965, a Air Wisconsin é uma companhia aérea regional estadunidense que não opera sob sua própria marca. Os bilhetes aéreos de seus quase 500 voos por dia são vendidos pela American Airlines para quem a Air Wisconsin presta serviço. A Air Wisconsin possui voos em quase 70 cidades estadunidenses e canadenses, transportando aproximadamente 6 milhões de passageiros por ano em seus 71 jatos regionais com capacidade para até 50 passageiros. 
A Republic Airlines é uma companhia aérea pertencente ao grupo Republic Airways que é também proprietário da empresa Shuttle America. Atualmente, a Republic Airlines opera voos regionais sob as marcas de três outras grandes empresas estadunidenses: US Airways Express, United Express e American Airlines, utilizando dois modelos de jatos regionais do tipo turbofan. No ano de 2015, entretanto, a Republic Airlines operava também turboélices bimotores de aproximadamente 70 assentos para a United Express. Os dados do BTS indicam que eram 27 turboélices e 131 jatos em operação naquele ano.

\section{RESULTADOS}

A Tabela 2 denota os cinco índices calculados referentes aos dados de 2015 das quatro companhias aéreas analisadas neste trabalho. São o consumo por assento, consumo por voo ou viagem, consumo por distância percorrida, consumo por passageiro transportado e consumo por payload ou carga paga.

Tabela 2 - Índices de consumo de combustível e load factor referentes ao ano de 2015

\begin{tabular}{lllllll}
\hline Empresa & $\begin{array}{l}\text { Índice 1 } \\
\text { (comb/ } \\
\text { seat) }\end{array}$ & $\begin{array}{l}\text { Índice 2 } \\
\text { (comb/ } \\
\text { voo) }\end{array}$ & $\begin{array}{l}\text { Índice 3 } \\
\text { (comb/ } \\
\text { dist) }\end{array}$ & $\begin{array}{l}\text { Índice 4 } \\
\text { (comb/ } \\
\text { pax) }\end{array}$ & $\begin{array}{l}\text { Índice 5 } \\
\text { (comb/ } \\
\text { payload) }\end{array}$ & Load Factor \\
\hline Island Air & $\underline{2,112}$ & $\underline{135,422}$ & 194,094 & $\underline{3,934}$ & $\underline{0,009}$ & $53,50 \%$ \\
Sun Country & 13,477 & 1999,993 & $\underline{12,313}$ & 17,104 & 0,050 & $78,87 \%$ \\
Air Wisconsin & 10,788 & 539,238 & 60,885 & 13,748 & 0,039 & $78,92 \%$ \\
Republic Airlines & 9,945 & 752,023 & 36,384 & 12,620 & 0,036 & $79,07 \%$ \\
\hline Fonte: BTS & & & & & &
\end{tabular}

O consumo de combustível em função do número de assentos de cada uma das empresas está associado ao tamanho das aeronaves utilizadas, pois quanto maior a aeronave, maior o número de assentos e se espera menor gasto de combustível por assento, estando ele ocupado ou não. A análise de desempenho destes dados demonstra que, diferentemente do que se esperava, o consumo de combustível por assento disponível foi maior na frota composta exclusivamente por jatos narrowbodies (SC) do que na frota exclusivamente formada por turboélices (IA). A frota de jatos regionais (AW) e a frota mista (AR) apresentaram desempenho similar.

O nível de ocupação das aeronaves pode influenciar o consumo de combustível por assento, pois, altera a massa transportada pela aeronave e consequentemente a quantidade de combustível necessária por assento. 0 consumo por passageiro transportado seguiu o mesmo padrão do índice por assento, porém com valores superiores, dado que nem sempre aeronaves voam totalmente ocupadas.

Ao se medir a quantidade de combustível por unidade de carga paga transportada, é possível identificar eventual substituição de passageiros por malotes postais, por exemplo. Neste índice, a frota turboélice expôs melhor resultado, seguida por RA com sua frota mista e AW com jatos regionais praticamente empatadas.

Para o mesmo período, o consumo de combustível por voo foi menor na companhia detentora exclusivamente de turboélices (IA) que naquelas detentoras de jatos. A Sun Country apresentou o maior índice, sendo Republic Airlines - operadora de jatos regionais e turboélices, em 2015 a segunda empresa menos econômica. 0 consumo de combustível em função da quantidade de voos de cada uma das empresas está associado não somente ao tipo utilizado de aeronave, mas também às características das rotas operadas. As rotas maiores da SC demandam maior quantidade absoluta de combustível por voo que as rotas menores da IA, por exemplo. 
Todavia, quando se analisa a quantidade de combustível consumida por unidade de distância voada, os jatos da SC apresentam melhor desempenho que os turboélices da IA. Esta aparente contradição deve-se ao fato da fase de cruzeiro ser mais econômica que as fases de subida à altitude de cruzeiro e posterior descida, de modo que o elevado consumo nestas duas últimas fases se dilui mais facilmente nas rotas maiores da SC. As rotas curtas da IA tornam seu consumo por distância voada maior que SC, pois o consumo associado às fases de decolagem e pouso representa consumo fixo independentemente da distância total voada.

A análise conjunta dos índices demonstra que IA é a mais econômica em quatro dos cinco índices analisados enquanto a SC é a menos econômica nos mesmos quatro índices. E justamente quando IA é a menos econômica, no consumo de combustível por unidade de distância percorrida, a SC é a mais econômica. No que concerne a AW e RA, elas ocupam a posição intermediária com resultados similares em três dos cinco índices. A exceção é quando se comparam consumo de combustível por voo e consumo de combustível por distância percorrida: ambas as empresas se alternam na condição de, em média, apresentar índice 1,5 superior à outra. A RA, entretanto, é mais econômica que a AW em quatro índices.

Ao se partir para análise DEA, cujos resultados são apresentados na Tabela 3, almeja-se verificar quais empresas são eficientes dado o conjunto analisado. Percebe-se que a Republic Airlines e Air Wisconsin são ineficientes frente às outras duas empresas quando se considera retorno constante de escala. Ambas, porém são eficientes quando se considera retorno variável.

Tabela 3 - Resultados DEA

\begin{tabular}{lllll}
\hline Empresa & Eficiência $\Theta_{\text {CRS }}$ & Eficiência $\Theta_{\text {VRS }}$ & \multicolumn{2}{c}{ Conjunto Referência (CRS) } \\
\hline Island Air & 1,000 & 1,000 & IA & SC \\
\cline { 2 - 2 } Sountry & 1,000 & 1,000 & & 0,381 \\
Air Wisconsin & 0,426 & 1,000 & 14,048 & 1,384 \\
Republic Airlines & 0,552 & 1,000 & 28,661 & \\
\hline
\end{tabular}

Dado que as quatro empresas são consideradas eficientes no consumo de combustível com a premissa VRS, é possível concluir que elas já adotam as melhores práticas possíveis dadas as suas condições e escala de operação. Entretanto, no modelo CRS, Air Wisconsin e Republic Airlines não seriam eficientes no consumo de combustível. Ou seja, teoricamente, ambas se beneficiariam de uma mudança de escala de modo a se aproximar de seu conjunto referência: Sun Country e Island Air.

Sendo empresas regionais, AW e RA são aquelas com perfil operacional mais próximo, ainda que não necessariamente atuem nas mesmas rotas e que tenham frotas distintas. Em consonância com os dados da Tabela 2, os resultados do DEA CRS indicam que, dentre elas, a empresa com frota mista possuiria eficiência superior no consumo de combustível. Uma hipótese para justificar este resultado é a possibilidade da RA alocar suas aeronaves conforme as características de suas rotas - embora este arranjo possa trazer complexidade na gestão da frota.

Os resultados do DEA também sugerem a necessidade de AW e RA se aproximarem mais do modelo operacional da IA, detentora de turboélices. Curiosamente, apenas $17 \%$ da frota da $R e$ public Airlines era composta por turboélices em 2015 e a empresa optou pela direção contrária: opera apenas jatos regionais neste ano de 2017. Cabe ressaltar que os dados disponíveis não permitem a identificação de qual aeronave operou determinada rota, bem como é desconhecida a malha aérea da RA nos dois momentos: 2015 quando operava jatos e turboélices, e 2017 
quando opera somente jatos. Portanto, não há informação suficiente para julgar apropriadamente a alteração de frota da Republic Airlines.

Aspectos práticos, contudo, podem impedir a transição de escala e a adequação do modelo operacional sugeridas pelos resultados do DEA. Há outros elementos não explorados neste trabalho, mas presumidos na função de produção definida pelo método DEA, que impactam a eficiência no consumo de combustível. São exemplos a demanda existente nas rotas de atuação, a competitividade no mercado de cada companhia aérea e até mesmo o nível de congestionamento de aeronaves existentes nos aeroportos operados por cada empresa.

\section{CONSIDERAÇÕES FINAIS}

Quando se analisam os índices de consumo de combustível, os resultados convergem com a literatura existente: encontrou-se melhor desempenho geral na empresa detentora de frota exclusiva de turboélices que foi seguida pela empresa com frota mista. Corrobora para esta conclusão principalmente o consumo de combustível por unidade de carga paga, pois, apesar de não muito frequente na literatura, é julgado pelos autores um parâmetro de comparação mais representativo das operações aéreas cotidianas, dado que permite a identificação de eventual substituição de passageiros por malotes postais em períodos de baixa demanda por viagens aéreas.

A Análise Envoltória de Dados, por sua vez, indicou que tanto Sun Country quanto Island Air são eficientes no consumo de combustível quando comparadas com Air Wisconsin e Republic Airlines. Como AW e RA não são percebidas como eficientes no consumo de combustível quando se utiliza modelo DEA CRS, o modelo sugere que existiria espaço para redução de custos e/ou aumento de produtividade destas empresas. A abordagem VRS, no entanto, demonstra que as quatro empresas são eficientes no consumo de combustível. Ou seja, AW e RA já apresentariam as melhores práticas, mas enfrentariam problema de escala.

0 presente estudo permitiu concluir que, dentre as empresas analisadas, aquelas que operaram turboélices no ano de 2015, tiveram um melhor desempenho em eficiência no consumo de combustível que aquelas detentoras de jatos. Dado que este estudo não aborda todas os condicionantes no modelo de negócio de cada companhia, não é possível afirmar categoricamente que os resultados são oriundos exclusivamente das diferenças entre turboélices e jatos.

As quatro companhias estudadas possuem características não exploradas neste trabalho que impactam a eficiência no consumo de combustível. São exemplos o modelo de negócios, a demanda existente nas rotas de atuação, a competitividade no mercado de cada companhia aérea e até mesmo o nível de congestionamento de aeronaves enfrentado nos aeroportos operados por cada empresa.

Como estudo futuro, é percebida a necessidade de se analisar a eficiência no consumo de combustível caso as rotas de cada uma das companhias fossem operadas por outro tipo de motor. Idealmente, uma comparação direta com voos executados nas mesmas condições - rota e carga paga - e variando-se apenas os sistemas de propulsão. É útil também verificar se as empresas realmente utilizam a motorização mais econômica para seu perfil operacional. Considerando o load factor indicado na Tabela 2, percebe-se que todas as companhias poderiam se beneficiar da utilização de aeronaves de menor capacidade ou talvez, de menor frequência de voos. 


\section{REFERÊNCIAS}

ABEAR, Panorama da Aviação Brasileira, http://panorama.abear.com.br/dados-e-estatisticas/custos-das-empresas/. Consultado em 28 de dezembro.

BABIKIAN, R.; LUKACHKO, S. P.; WAITZ, I. A. The historical fuel efficiency characteristics of regional aircraft from technological, operational and cost perspectives. Journal of Air Transport Management, p. 389-400, 2002. DOI: 10.1016/S09696997(02)00020-0

BONACCORSI, A.; GIURI, P. When shakeout doesn't occur: The evolution of the turboprop engine industry. Research Policy, v. 29, p. 847-870, 2000. DOI: 10.1016/S0048-7333(00)00109-8

BRUECKNER, J. K., and PAI, V.; "Technological innovation in the airline industry: the impact of regional jets." International Journal of Industrial Organization, v. 27, p. 110-120, 2009. DOI: 10.1016/j.ijindorg.2008.05.003

GIVONI, M.; RIETVELD, P. The environmental implications of airlines' choice of aircraft size. Journal of Air Transport Management, 2010. DOI: 10.1016/j.jairtraman.2009.07.010

KARLAFTIS, M., TSAMBOULAS, D.; Efficiency measurement in public transport: are findings specification sensitive? Transportation Research Part A, v, 46, p. 392-402, 2012. DOI: 10.1016/j.tra.2011.10.005

REINAS, R. I.; MARIANO, E. B.; REBELATTO, D. A. N.. Custo/benefício de aeronaves: uma abordagem pela Análise Envoltória de Dados. Produção, p. 684-695, 2011.

RYERSON, M. S.; GE, X. The role of turboprops in China's growing aviation system. Journal of Transport Geography, p. article in press, 2014. DOI: 10.1016/j.jtrangeo.2014.03.009

RYERSON, M. S.; HANSEN, M. The potential of turboprops for reducing aviation fuel consumption. Transportation Research Part D, p. 305-314, 2010. DOI: 10.1016/j.trd.2010.03.003

RYERSON, M. S.; HANSEN, M. Capturing the impact of fuel price on jet aircraft operating costs with Leontief technology and econometric models. Transportation Research Part C, v. 33, p. 282-296, 2013. DOI: 10.1016/j.trc.2011.05.015

SHERMAN, H. D.; ZHU, J. Service Productivity Management, Improving Service Performance with DEA. 328p, 2006. DOI: 10.1007/0-387-33231-6

TOFALLIS, C.; Input efficiency profiling: an application to airlines. Computers. Ops Res, v. 24, p. 253-258, 1997. DOI: 10.1016/S0305-0548(96)00067-6

TONA, C.; RAVIOLO, P. A.; PELLEGRINI, L. F.; OLIVEIRA JÚNIOR, S. Exergy and thermoeconomic analysis of a turbofan engine during a typical commercial flight. Energy, 2010. DOI: 10.1016/j.energy.2009.06.052

ZOU, B.; ELKE, M.; HANSEN, M.; KAFLE, N. Evaluating air carrier fuel efficiency in the US airline industry. Transportation Research Part A, 59, 2014. 306-330. DOI: 10.1016/j.tra.2013.12.003 